\title{
Anti-cancer Activity of Osmanthus matsumuranus Extract by Inducing G2/M Arrest and Apoptosis in Human Hepatocellular Carcinoma Hep G2 Cells
}

ORIGINAL

ARTICLE

\section{Soojung Jin ${ }^{1,2}$, Hyun-Jin Park ${ }^{1}$, You Na Oh ${ }^{1}$, Hyun Ju Kwon ${ }^{1,2}$, Jeong-Hwan Kim ${ }^{1}$, Yung Hyun Choi ${ }^{1,3,4}$, Byung Woo Kim ${ }^{1,2}$}

${ }^{1}$ Blue-Bio Industry Regional Innovation Center, Dong-Eui University, ${ }^{2}$ Department of Life Science and Biotechnology, College of Natural Sciences and Human Ecology, Dong-Eui University, ${ }^{3}$ Department of Biochemistry, College of Korean Medicine, Dong-Eui University, ${ }^{4}$ Anti-Aging Research Center, Dong-Eui University, Busan, Korea

\begin{abstract}
Background: Osmanthus matsumuranus, a species of Oleaceae, is found in East Asia and Southeast Asia. The bioactivities of 0 . matsumuranus have not yet been fully understood. Here, we studied on the molecular mechanisms underlying anti-cancer effect of ethanol extract of 0 . matsumuranus (EEOM).

Methods: Inhibitory effect of EEOM on cell growth and proliferation was determined by WST assay in various cancer cells. To investigate the mechanisms of EEOM-mediated cytotoxicity, HepG2 cells were treated with various concentration of EEOM and analyzed the cell cycle arrest and apoptosis induction by flow cytometry, Western blot analysis, 4,6-diamidino-2-phenylindole (DAPI) staining and DNA fragmentation.

Results: EEOM showed the cytotoxic activities in a dose-dependent manner in various cancer cell lines but not in normal cells, and HepG2 cells were most susceptible to EEOM-induced cytotoxicity. EEOM induced G2/M arrest in HepG2 cells associated with decreased expression of cyclin-dependent kinase 1 (CDK1), cyclin A and cylcin B, and increased expression of phospho-checkpoint kinase 2, p53 and CDK inhibitor p21. Immunofluorescence staining showed that EEOM-treated HepG2 increased doublet nuclei and condensed actin, resulting in cell rounding. Furthermore, EEOM-mediated apoptosis was determined by Annexin $V$ staining, chromatin condensation and DNA fragmentation. EEOM caused upregulation of FAS and Bax, activation of caspase-3, $-8,-9$, and fragmentation of poly ADP ribose polymerase.

Conclusions: These results suggest that EEOM efficiently inhibits proliferation of HepG2 cells by inducing both G2/M arrest and apoptosis via intrinsic and extrinsic pathways, and EEOM may be used as a cancer chemopreventive agent in the food or nutraceutical industry. (J Cancer Prev 2015;20:241-249)
\end{abstract}

Key Words: Anticancer effect, Apoptosis, Cell cycle arrest, Hep G2 cells, Osmanthus matsumuranus

\section{INTRODUCTION}

Hepatic cancer, a cancer that originates in the liver, is the sixth most common cancer and the second leading cause of cancer death in the world. ${ }^{1,2}$ In 2012, it occurred in 782,000 cases and resulted in 746,000 deaths, which was $9.1 \%$ of total cancer death. ${ }^{2}$ Due to the limitation of hepatic cancer treatment, such as surgery and transplantation, chemopreventive and chemotherapeutic approaches of naturally occurring compounds and extracts have received increasing attention in recent years. ${ }^{3-6}$

Cancer is characterized with an unregulated cell growth to invade or spread out to other organs of the body. ${ }^{7}$ For their abnormal cell growth, cancer cells can undergo limitless replication by deregulation of cell cycle and evade apoptosis. Therefore, inducing the cell cycle arrest and apoptosis of cancer cells is being an outstanding strategy for cancer chemoprevention and chemo-

Received November 2, 2015, Revised November 23, 2015, Accepted November 23, 2015

Correspondence to: Byung Woo Kim

Blue-Bio Industry Regional Innovation Center, Dong-Eui University, 176 Eomgwang-ro, Busanjin-gu, Busan 47340, Korea

Tel: +82-51-890-2900, Fax: +82-505-182-6951, E-mail: bwkim@deu.ac.kr

Copyright (C) 2015 Korean Society of Cancer Prevention

(c) This is an Open Access article distributed under the terms of the Creative Commons Attribution Non-Commercial License (http://creativecommons.org/licenses/by-nc/4.0) which permits unrestricted non-commercial use, distribution, and reproduction in any medium, provided the original work is properly cited. 
therapeutics. ${ }^{8}$ It has been reported that many natural compounds and extracts are modulating cell cycle regulation and apoptosis. ${ }^{9.11}$ Cell cycle progression is controlled by cyclin-dependent kinase (CDK)/cyclin complexes, and CDK1/cyclin A and CDK1/cyclin B complexes are the key molecules of G2/M checkpoint. ${ }^{12}$ The activation of $\mathrm{CDK} /$ cyclin complex promotes cell cycle progression, while most of damage signals of cells induce cell cycle arrest by activating p53 via CHK2 to repair damaged DNA. ${ }^{13}$ Activated p53 induces the transcription of $\mathrm{p} 21, \mathrm{a} \mathrm{CDK}$ inhibitor, which can suppress G2/M transition by the inactivation of $\mathrm{CDK} / \mathrm{cyclin}$ complex. ${ }^{14}$

Apoptosis, programmed cell death, occurs in multicellular organisms and plays an important role in the regulation and maintenance of physiological conditions. It leads to various biochemical events including cell shrinkage, blebbing, nuclear fragmentation, and chromatin condensation. ${ }^{15}$ The mechanisms of apoptosis are divided into two pathways. One is the extrinsic pathway via death receptor and the other is the mitochondrial intrinsic pathway. ${ }^{16}$ The ligation of death receptors and their ligands induces the formation of a death-inducing signaling complex, followed by the caspase- 8 activation. Activated caspase- 8 can transmit the apoptotic signals both in directly via caspase-3 activation and in indirectly via activation of proapoptotic B-cell lymphoma 2 (Bcl-2) family proteins. ${ }^{17}$ Activation of pro-apoptotic Bcl-2 family proteins can induce the mitochondrial permeabilization, resulting in the release of cytochrome $c$ into the cytosol. In the intrinsic pathway, released cytochrome $c$ can activate caspase-9, and then activated caspase-9 induces the cleavage of procaspase-3. Cleaved caspase- 3 through the extrinsic and intrinsic pathways can interact with its substrates, including PARP involved in DNA repair, finally resulting in cell death. ${ }^{18}$

$O$. matsumuranusis a species of flowering plants in the family Oleaceae. Using the flowers of $\mathcal{O}$. fragrans, osmanthus tea is traditionally consumed in East Asia and it has been known for its anti-oxidative effects. ${ }^{19}$ However, the bioactivity of $\mathcal{O}$. matsumuranus remains still unclear. In this study, we investigated the anti-cancer activity of $\mathcal{O}$. matsumuranus and the molecular mechanism of its anti-cancer effect on human hepatocellular carcinoma HepG2 cells.

\section{MATERIALS AND METHODS}

\section{Preparation of Osmanthus matsumuranus extract}

The ethanol extract of $O$. matsumuranus (EEOM) was obtained from International Biological Material Research Center, Korea (FBM123-099). Plant material of $O$. matsumuarnus was extracted with $95 \%$ ethanol at $45^{\circ} \mathrm{C}$ using a sonicator, evaporated and freeze-dried. EEOM was dissolved in dimethyl sulfoxide (DMSO) and stored at $-20^{\circ} \mathrm{C}$ prior to use.

\section{Cell culture}

Human hepatocellular carcinoma HepG2, human colon adenocarcinoma HT29, human lung adenocarcinoma A549 and human fetal lung cells IMR90 cells were purchased from American Type Culture Collection (ATCC; Rockville, MD, USA). Cells were cultured in Dulbecco's modified Eagle's medium supplemented with $10 \% \mathrm{FBS}$, penicillin and streptomycin at $37^{\circ} \mathrm{C}$ and $5 \% \mathrm{CO}_{2}$.

\section{Cell viability assay and morphological study}

Measurement of cell viability was determined using the EZ-Cytox cell viability assay kit (Daeillab, Seoul, Korea). Cells were plated at a density of 2 to $5 \times 10^{4}$ cells/well in 24-well plates and treated with media containing DMSO as control or various concentrations of EEOM for 48 hours. EZ-Cytox assay reagent (10 $\mu \mathrm{L})$ was added to each cell culture well, and the mixture was incubated for 30 minutes at $37^{\circ} \mathrm{C}$. The absorbance was measured at $450 \mathrm{~nm}$ using a plate reader (Beckman Coulter, Fullerton, CA, USA). For morphological study, HepG2 cells were treated with EEOM for 48 hours and directly photographed with an inverted microscope using Axio Vision program.

\section{Cell cycle analysis}

The effects of EEOM on the cell cycle in HepG2 cells were examined using the Muse ${ }^{\mathrm{TM}}$ Cell Cycle kit (Merck Millipore, Darmstadt, Germany) according to the manufacturer's instructions. Briefly, cells $\left(1 \times 10^{5}\right.$ cells/well $)$ were plated in 6-well plate and treated with $0.1 \%$ DMSO as vehicle control or with various concentration of EEOM for 48 hours. The cells were then harvested, washed once with PBS, and fixed in cold 70\% ethanol for 3 hours at $-20^{\circ} \mathrm{C}$. Fixed cells were centrifuged at $300 \times g$ for 5 minutes and resuspended in PBS. After addition of an equal volume of Muse ${ }^{\mathrm{TM}}$ Cell Cycle reagent, cells were incubated for 30 minutes at room temperature in the dark. Finally, flow cytometry was conducted (Muse ${ }^{\mathrm{TM}}$ Cell Analyzer; Merck Millipore) and the Muse analysis software (ver. 1.4) was used to determine the relative DNA content.

\section{Western blot analysis}

EEOM-treated cells were treated with lysis buffer $(20 \mathrm{mM}$ Tris-HCl [pH 7.5], $150 \mathrm{mM} \mathrm{NaCl}, 1 \mathrm{mM}$ ethylenediaminetetraacetic acid [EDTA], $1 \mathrm{mM}$ ethylene glycol tetraacetic acid, 1\% 
Triton X-100, $1 \mu \mathrm{g} / \mathrm{mL}$ leupeptin, $1 \mathrm{mM}$ phenylmethylsulfonyl fluoride) for 15 minutes on ice, disrupted by sonication and centrifuged for 30 minutes at 13,000 rpm. For preparation of cytosolic proteins, the sonication process of the above procedure was omitted. ${ }^{20}$ The proteins in the supernatant were collected and the concentration of protein was determined by Bradford method. For Western blot analysis, 30 to $50 \mu \mathrm{g} / \mathrm{mL}$ of proteins were resolved by sodium dodecyl sulfate-polyacrylamide gel electrophoresis and blotted onto nitrocellulose membranes. Blots were incubated at $4^{\circ} \mathrm{C}$ overnight with specific primary antibodies followed by horseradish peroxidase-conjugated secondary antibodies and visualized by an enhanced chemiluminescence detection system (FluoChem ${ }^{\circledR}$ FC2; AlphaInnotech, San Leandro, CA, USA) using Western blotting luminol reagent (Santa Cruz Biotechnology, Dallas, TX, USA). CDK1, Cyclin A, Cyclin B, p53, Fas, Bax, caspase-3, caspase-8, caspase-9, PARP, actin primary antibodies and peroxidase-conjugated secondary antibodies were from Santa Cruz Biotechnology. Primary antibodies against CHK2, p-CHK2 (Thr68), p-p53 (Ser20), p21, and Bcl-2 were purchased from Cell Signaling Technology (Beverly, CA, USA).

\section{Immunofluorescence staining}

The cells $\left(2.5 \times 10^{4}\right.$ cells/well $)$ were plated in 8-chamber slides and treated with $0.1 \%$ DMSO as vehicle control or with various concentration of EEOM for 48 hours after serum starvation. The cells were fixed in $4 \%$ formaldehyde for 15 minutes at room temperature and rinsed three times in PBS. Non-specific interactions were blocked by normal donkey serum in $0.3 \%$ Triton X-100 for 1 hour, and then cells were incubated with primary antibody (goat anti-actin antibody; Santa Cruz Biotechnology) at $4^{\circ} \mathrm{C}$ overnight. After washing, cells were incubated with fluoresce in isothiocyanate (FITC)-labelled secondary antibody (donkey anti-goat immunoglobulin G-FITC; Santa Cruz Biotechnology) for 1 hour at room temperature. Cells were rinsed with PBS for three times and then stained with 4',6-diamidino-2-phenylindole (DAPI; Sigma, St. Louis, MO, USA) for 10 minutes. After mounting, the stained cells were observed using fluorescence microscope (Carl Zeiss, Jena, Germany).

\section{Apoptosis analysis}

Apoptotic cells were measured using Muse ${ }^{\mathrm{TM}}$ Annexin V \& Dead Cell Kit (Merck Millipore) according to the manufacturer's instructions. In brief, HepG2 cells were treated with vehicle control or various concentrations of EEOM for 48 hours. Cells were harvested, washed and resuspended in $1 \%$ FBS/PBS. Cells were then mixed with an equal volume of Muse ${ }^{\mathrm{TM}}$ Annexin V \&
Dead Cell reagent and incubated for 20 minutes at room temperature in the dark. Without washing, cells were analyzed with the Muse ${ }^{\mathrm{TM}}$ Cell Analyzer and the Muse analysis software.

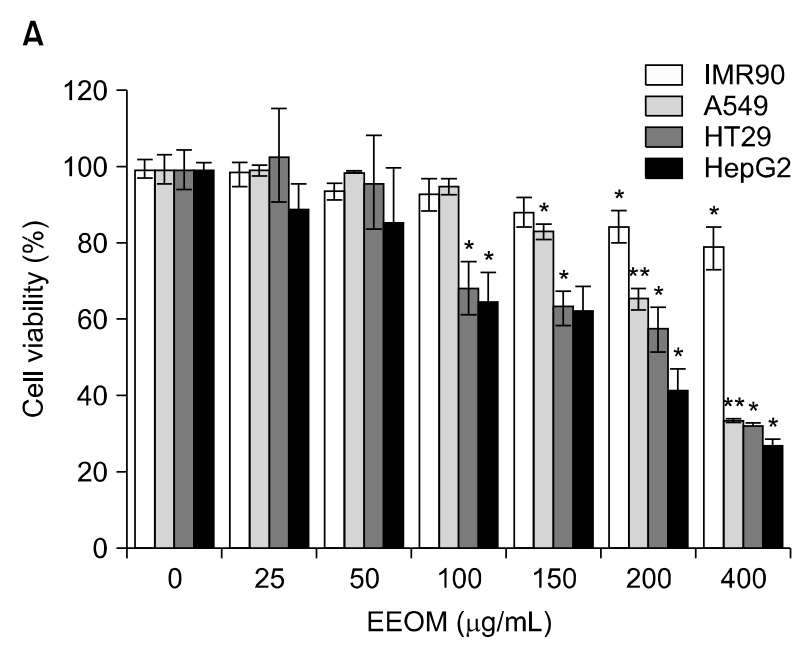

B

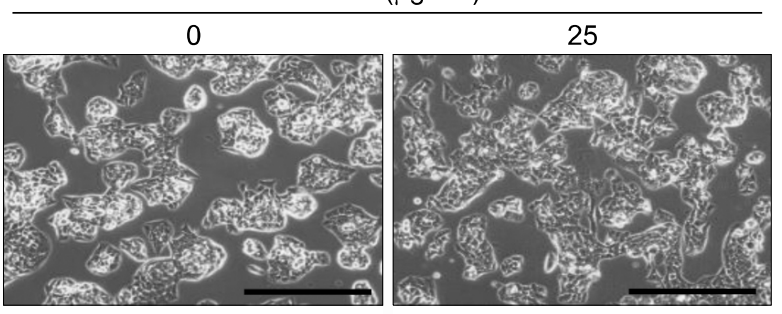

50

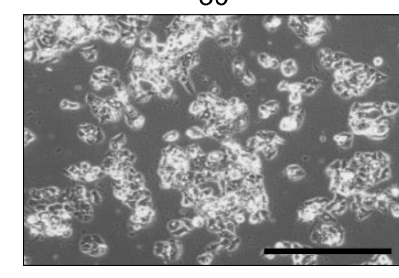

100

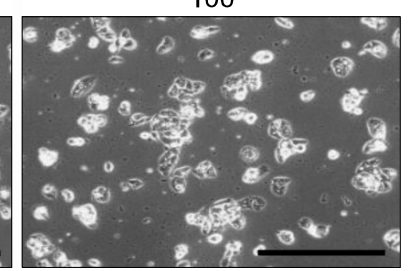

Figure 1. Effect of ethanol extract of Osmanthus matsumuranus (EEOM) on cancer cell growth and morphology of HepG2 cells. (A) Human fetal lung IMR90 cell line as a normal cell line and various cancer cell lines, such as human lung adenocarcinoma A549 cells, human colon adenocarcinoma HT29 cells and human hepatocellular carcinoma HepG2 cells, were treated with indicated concentration of EEOM for 48 hours. Various cancer cell lines, such as human lung adenocarcinoma A549 cells, human colon adenocarcinoma HT29 cells and human hepatocellular carcinoma HepG2 cells, were treated with indicated concentration of EEOM for 48 hours. Cytotoxic effect of EEOM was determined by WST assay. Results are expressed as percentage of the vehicle treated control $\pm \mathrm{SD}$ of three independent experiments. $* P<0.05$ and $* * P<0.01$ compared with dissolved in dimethyl sulfoxide treated cells. (B) Morphological changes by EEOM in HepG2 cells. The cells were incubated with indicated concentration of EEOM for 48 hours, and then visualized by light microscopy. Scale bars, $200 \mu \mathrm{m}$. 


\section{Nuclear staining with DAPI}

EEOM-treated cells were fixed with $4 \%$ formaldehyde for 20 minutes at room temperature. Fixed cells were permeabilized with $0.5 \%$ Triton X-100 in PBS for 10 minutes at room temperature. After washing with PBS, cells were incubated with $1 \mu \mathrm{g} / \mathrm{mL}$ of DAPI for 10 minutes and then washed three times in PBS. Apoptotic nuclei (condensed chromatin) were examined by fluorescence microscopy (Carl Zeiss).

A

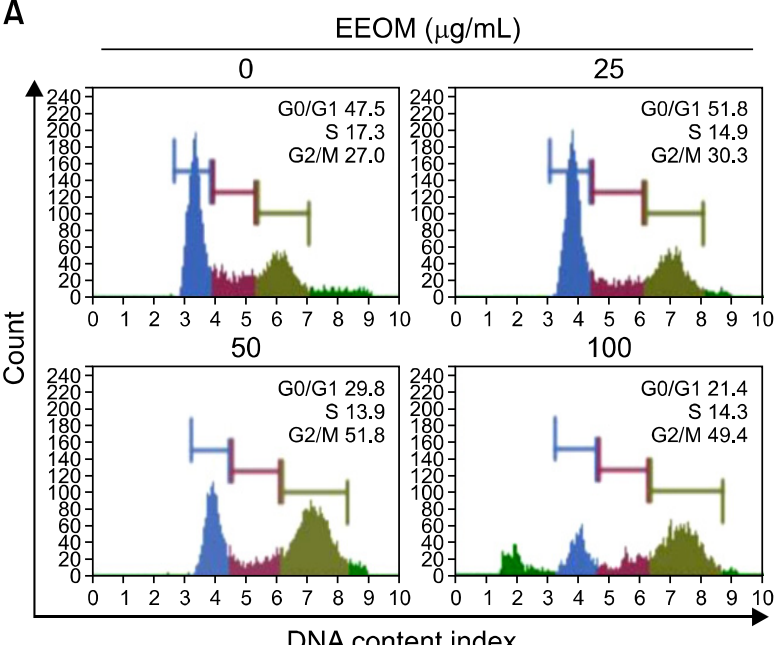

C

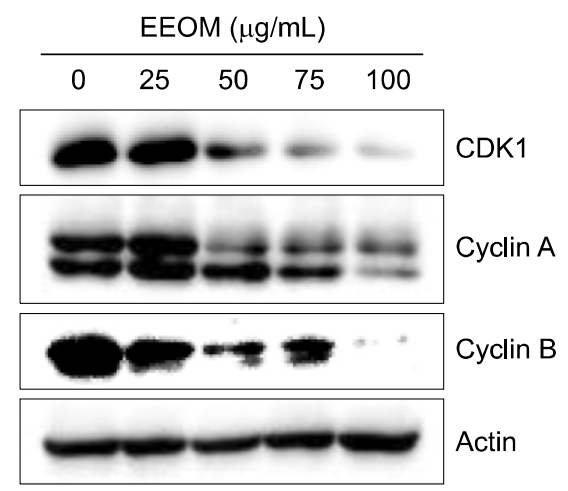

\section{DNA fragmentation}

After treatment of HepG2 cells with EEOM, harvested cells were lysed with a hypotonic lysis buffer (10 mM Tris- $\mathrm{HCl}$ [pH 7.4], 5 mM EDTA [pH 8.0], 0.2\% Triton X-100) for 30 minutes on ice, followed by centrifugation at $12,000 \times g$ for 30 minutes. RNA in the supernatants was removed by RNase A $(0.1 \mathrm{mg} / \mathrm{mL})$ for 2 hours at $37^{\circ} \mathrm{C}$ and then proteinase $\mathrm{K}(0.2 \mathrm{mg} / \mathrm{mL})$ was treated for 3 hours at $60^{\circ} \mathrm{C}$. DNA was extracted with a mixture of phenol, chloroform, and isoamyl alcohol (25:24:1) and precipitated with

B

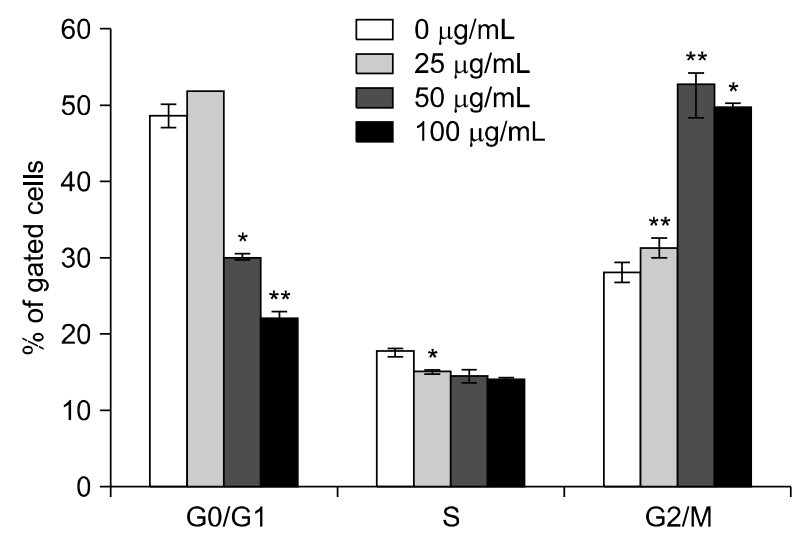

D

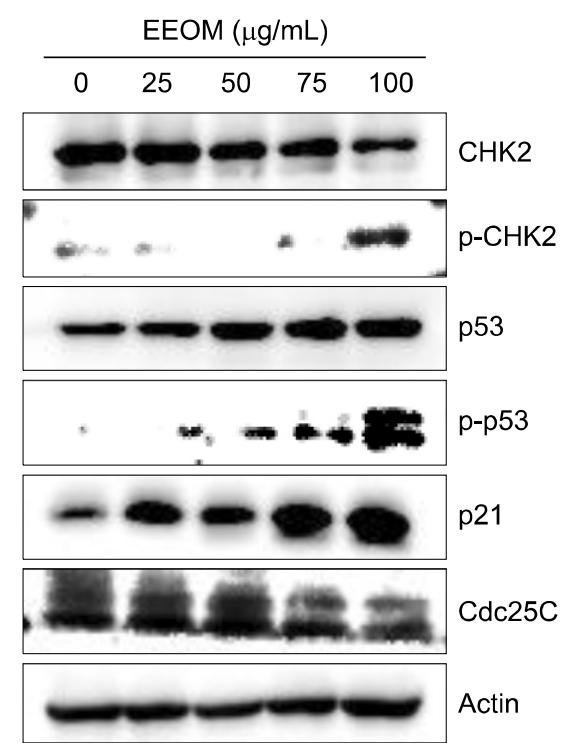

Figure 2. Induction of G2/M arrest by ethanol extract of Osmanthus matsumuranus (EEOM) treatment in HepG2 cells. (A, B) Cell cycle analysis. HepG2 cells were treated with indicated concentration of EEOM for 48 hours, stained with propidium iodide for 30 minutes and analyzed by flow cytometry. DNA-fluorescence histogram (A) and the percentage of gated cells (B) are shown. $* P<0.05$ and $* * P<0.01$ compared with cell population of DMSO treated control. (C, D) Western blot analysis. Cells were treated with EEOM for 48 hours and lysed in extraction buffer, followed by Western blot analysis using with primary antibodies against G2/M checkpoint proteins (C) and CHK2/p53 pathway proteins (D). CDK, cyclin-dependent kinase. 
ethanol. Extracted DNA was electrophoretically separated on a $2 \%$ agarose gel containing $1 \mu \mathrm{g} / \mathrm{mL}$ ethidium bromide and visualized under ultraviolet transillumination.

\section{Statistical analysis}

The data are presented as the mean \pm SD from at least three independent experiments. Statistical comparisons between groups were performed by IBM SPSS program ver. 21 (IBM Co., Armonk, NY, USA) followed by Student $t$-test. A value of $P<0.05$ was considered statistically significant.

EEOM

$(\mu \mathrm{g} / \mathrm{mL})$

DAPI

Actin

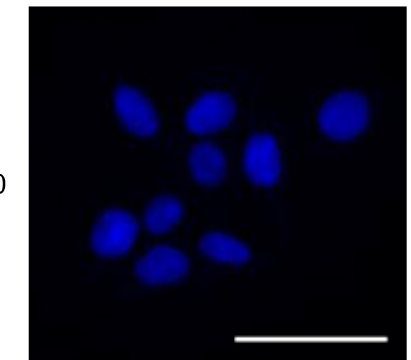

50

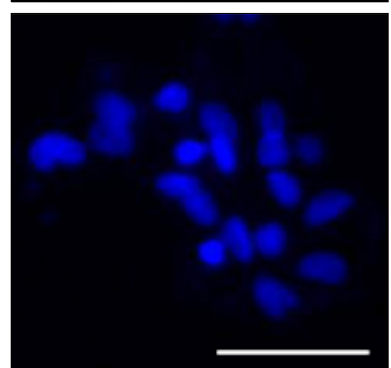

75
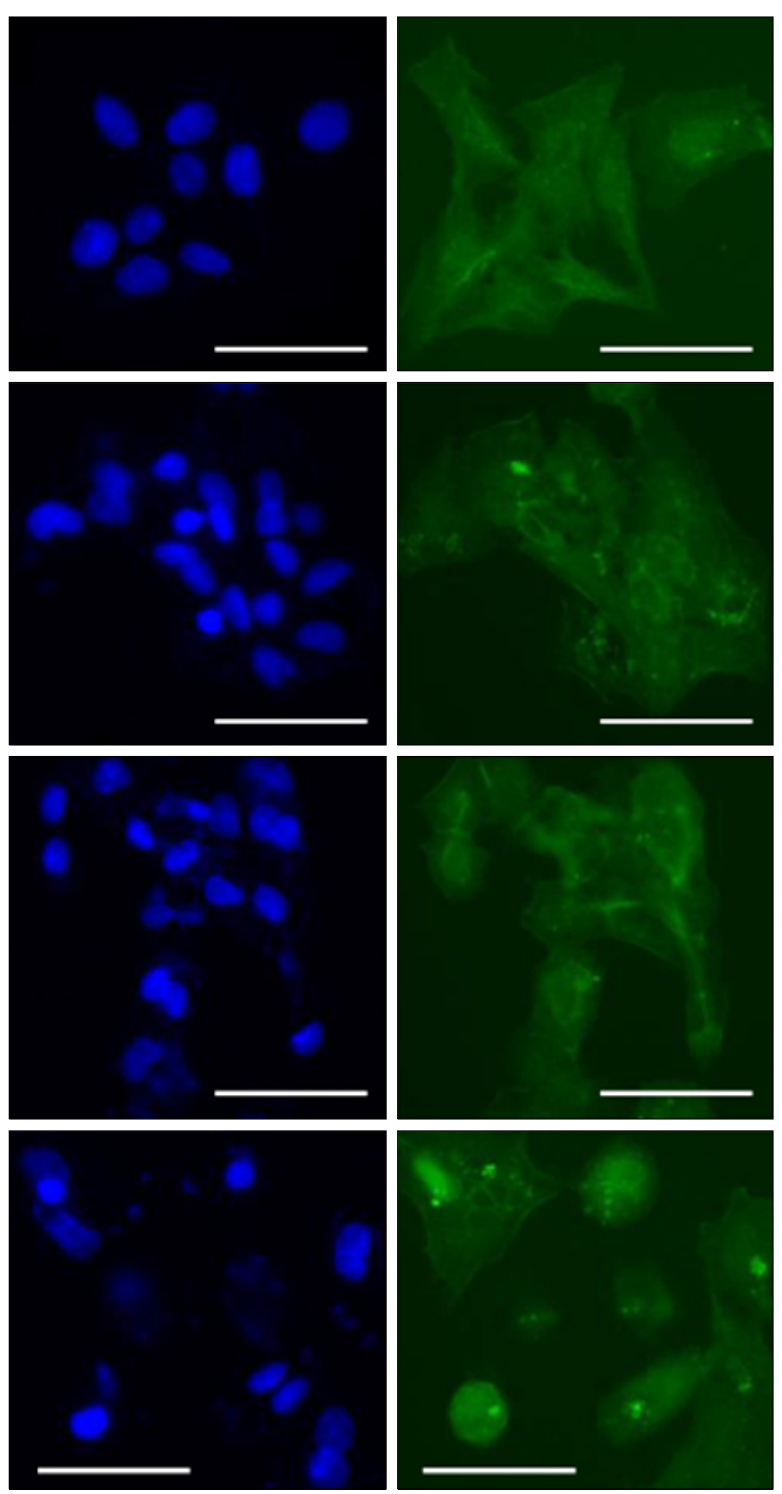

\section{RESULTS}

1. Osmanthus matsumuranus extract inhibits the cell growth of various cancer cells

To investigate the anti-cancer activity of EEOM, we first examined the effect of EEOM on cancer cell growth using human hepatocellular carcinoma HepG2 cells, human colon adenocarcinoma HT29 cells and human lung adenocarcinoma A549 cells. As shown in Figure 1A, EEOM inhibited the growth of cancer cell lines in a dose-dependent manner and HepG2 cells were most susceptible to EEOM-induced cytotoxicity. Increasing concentrations of EEOM caused increasing floating cells and decreasing viable adherent HepG2 cells (Fig. 1B). However, EEOM did not
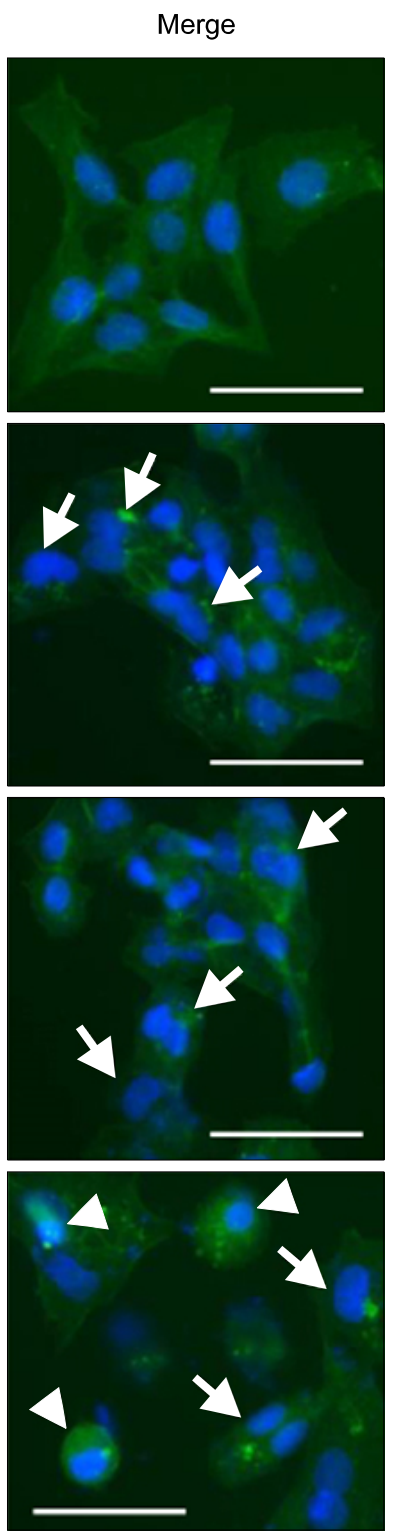

Figure 3. Immunofluorescence images of ethanol extract of Osmanthus matsumuranus (EEOM)-treated HepG2 cells. Cells were treated with EEOM for 48 hours and then fixed with $4 \%$ formaldehyde. Fixed cells were stained with actin-specific antibody, followed by fluoresce in isothiocyanate-conjugated secondary antibody. 4',6-diamidino-2-phenylindole (DAPI) was used for nuclear staining. Arrows indicate cells with double nuclei and arrowheads show cell rounding. Scale bars, $50 \mu \mathrm{m}$. 
show any significant inhibitory effect of proliferation in human normal fetal lung IMR90 cells. Therefore, we decided to examine the molecular mechanism of cytotoxic activity of EEOM in HepG2 cells.

\section{Osmanthus matsumuranus extract induces $\mathrm{G} 2 / \mathrm{M}$ phase arrest in HepG2 cells}

To elucidate the cytotoxic effect of EEOM in HepG2 cells, cell cycle analysis was performed by flow cytometry. Cell population in $\mathrm{G} 2 / \mathrm{M}$ phase was increased in a dose-dependent manner, accompanied by a decrease in the G0/G1 and S phases (Fig. 2A). As shown in Figure 2B, the percentage of cells in $\mathrm{G} 2 / \mathrm{M}$ phase was increased from $27.9 \%$ to $52.8 \%$ by EEOM treatment $(50 \mu \mathrm{g} / \mathrm{mL})$. By the treatment with $100 \mu \mathrm{g} / \mathrm{mL}$ of EEOM, cells in G2/M phase were slightly decreased, whereas cells in SubG1 phase were increased compared to those of $50 \mu \mathrm{g} / \mathrm{mL}$ treatment (Fig. 2A). We next examined the expression of G2/M transition-related proteins by Western blot analysis to understand the molecular basis for the EEOM-induced G2/M arrest. As shown in Figure 2C, EEOM significantly decreased the protein levels of CDK1, cyclin A and cyclin B in a dose-dependent manner. Since it is well studied that $\mathrm{CDK} /$ cyclin complex can be negatively regulated by $\mathrm{CHK} 2 / \mathrm{p} 53$
A

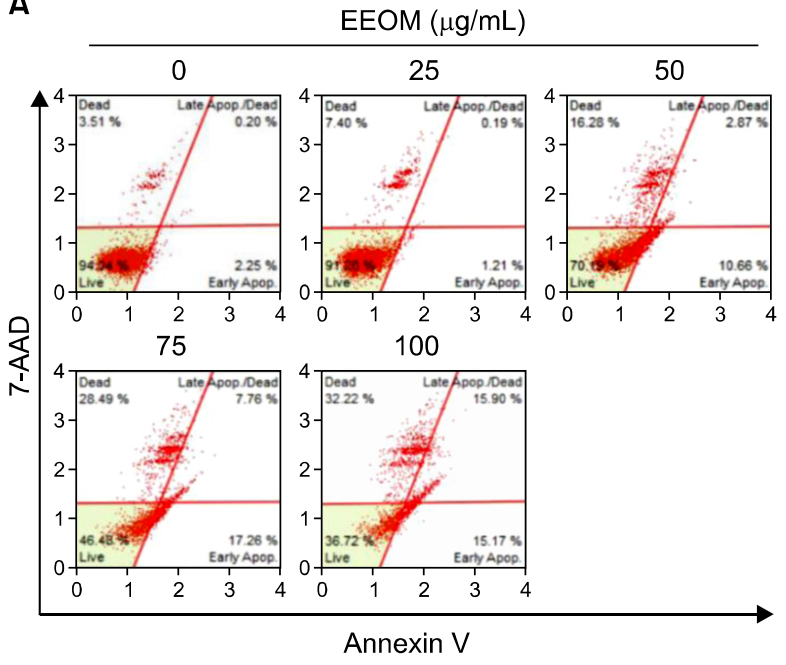

C

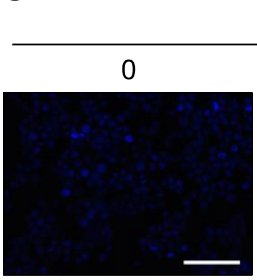

75

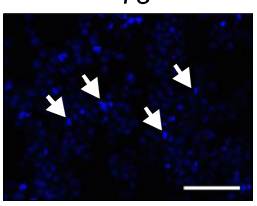

$\operatorname{EEOM}(\mu \mathrm{g} / \mathrm{mL})$

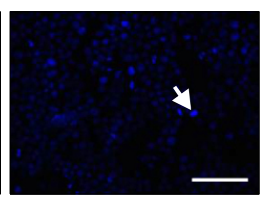

100

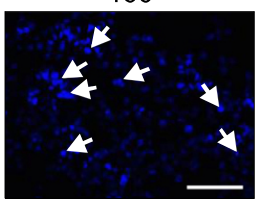

B

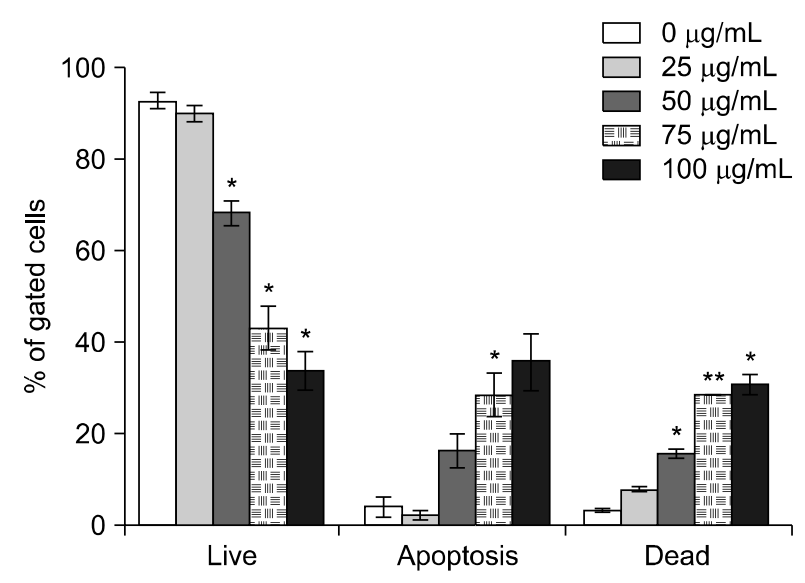

D

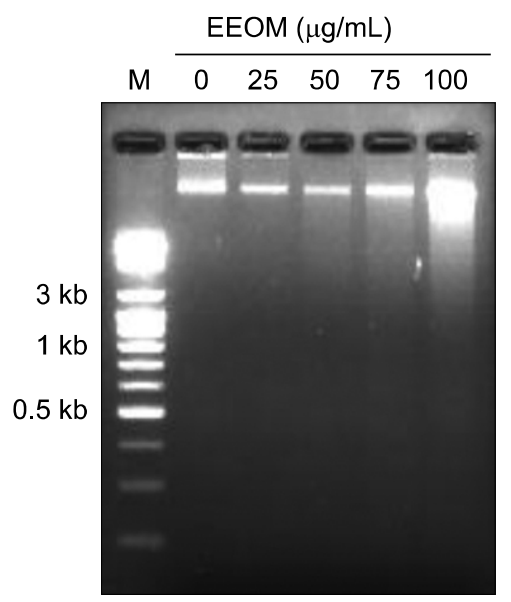

Figure 4. Apoptosis induction by ethanol extract of Osmanthus matsumuranus (EEOM) in HepG2 cells. (A, B) Annexin V/7-Aminoactinomycin D (7-AAD) double staining. Cells were treated with EEOM for 48 hours and double stained with Annexin V and 7-AAD. Dot blot (A) and the percentage of live, total apoptotic and dead cells (B) are shown. Live cells (lower left): Annexin $\mathrm{V}^{-} / 7-\mathrm{AAD}^{-}$, dead cells (upper left): Annexin $\mathrm{V}^{-} / 7-\mathrm{AAD}^{+}$, early apoptotic cells (lower right): Annexin $\mathrm{V}^{+} / 7-\mathrm{AAD}^{-}$, late apoptotic cells (upper right): Annexin $\mathrm{V}^{+} / 7-\mathrm{AAD}^{+}$. $* P<$ 0.05 and $* * P<0.01$ compared with cell population of dissolved in dimethyl sulfoxide treated control. (C) 4',6-diamidino-2-phenylindole (DAPI) staining. EEOM-treated cells were fixed, permeabilized and stained with DAPI. Arrows indicate the apoptotic bodies. Scale bars, 100 $\mu \mathrm{m}$. (D) DNA fragmentation. DNA was extracted from EEOM-treated HepG2 cells and DNA fragmentation was examined by agarose gel electrophoresis. Lane M, $1 \mathrm{~kb}$ DNA ladder. 
A

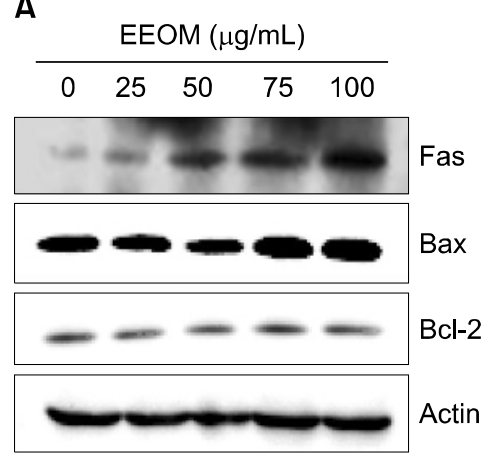

B

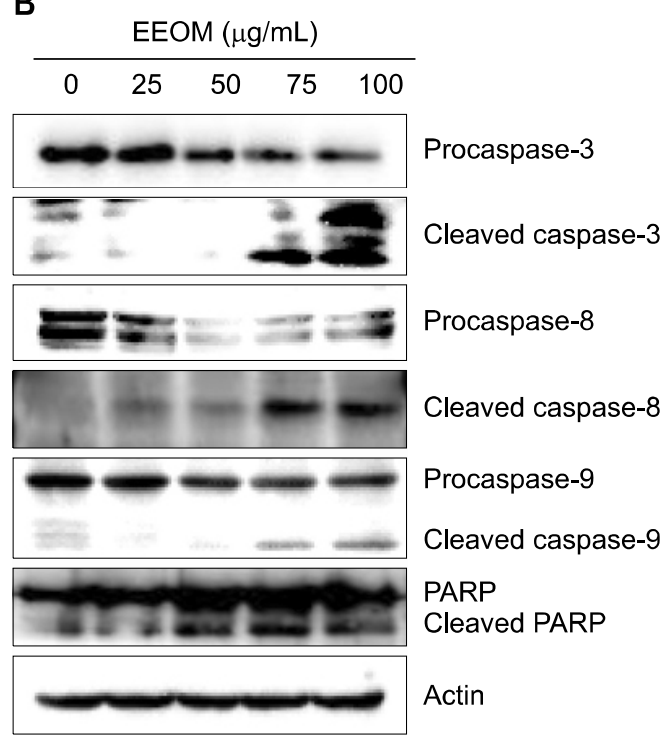

Figure 5. Effect of ethanol extract of Osmanthus matsumuranus (EEOM) on the expression of apoptotic proteins. EEOM-treated HepG2 cells were harvested and then proteins were isolated. The apoptotic protein expressions (A: Fas, Bax, Bcl-2; B: caspase-3, caspase-8, caspase-9, PARP) were estimated by Western blot analysis. pathway, ${ }^{14}$ we determined the effect of EEOM on $\mathrm{p} 53$ pathway. Figure 2D showed that EEOM activated CHK2 via phosphorylation, and induced the expression and phosphorylation of $\mathrm{p} 53$ in a dose-dependent manner. The expression of CDK inhibitor p21, a downstream protein of $\mathrm{p} 53$, was increased by EEOM. However, the significant difference was not found in the expression of Cdc25C. These results indicate that EEOM brings about a remarkable G2/M arrest by p21 induction via CHK2/p53 pathway in HepG2 cells.

\section{Osmanthus matsumuranus extract increases double nuclei in HepG2 cells}

In order to further examine the morphological changes of EEOM-mediated G2/M arrest, we performed immunofluorescence staining with anti-actin antibody and DAPI. As shown in Figure 3, the shape of HepG2 cells was flattened and polygonal with well-organized actin fibers in the absence of EEOM treatment. On the contrary, EEOM-treated cells (Fig. 3 arrows) showed clustering of actin fibers and doublet nuclei mostly joined or bridged together. Moreover, some cells (Fig. 3 arrowheads) treated with $100 \mu \mathrm{g} / \mathrm{mL}$ of EEOM showed the condensation of nucleus and aggregation of actin, resulting in cell rounding.

\section{Osmanthus matsumuranus extract induces apoptosis in HepG2 cells}

Since HepG2 cells in SubG1 phase were increased by EEOM treatment (Fig. 2A), EEOM-mediated apoptosis was examined by flow cytometry analysis using Annexin V/7-Aminoactinomycin D (7-AAD) double staining. EEOM increased both early apoptotic
(Annexin $\mathrm{V}^{+} / 7-\mathrm{AAD}^{-}$) and late apoptotic cells (Annexin $\mathrm{V}^{+}$/ 7-AAD ${ }^{+}$) in a dose-dependent manner (Fig. 4A). According to Figure $4 \mathrm{~B}$, the percentage of apoptotic $\left(\right.$ Annexin $\mathrm{V}^{+}$) cells was increased from $4.03 \%$ to $35.56 \%$ by treatment with $100 \mu \mathrm{g} / \mathrm{mL}$ of EEOM. As nuclear condensation and DNA fragmentation are the remarkable characteristics of apoptosis, ${ }^{15}$ we next confirmed the EEOM-induced apoptosis by using DAPI staining and DNA fragmentation assay. As shown in Figure 4C, apoptotic bodies with chromatin condensation were observed in EEOM-treated HepG2 cells in a concentration-dependent manner. Clumpy chromatin condensation was easily detected in $100 \mu \mathrm{g} / \mathrm{mL}$ EEOMtreated HepG2 cells. Figure 4D showed that the chromosomal DNA of HepG2 cells was degraded by EEOM, resulting in the broad smearing and fragmented bands.

5. Osmanthus matsumuranus extract regulates the expression and activation of apoptotic proteins

In order to investigate the effect of EEOM on the expression and activation of apoptosis-related molecules in the protein levels, we performed Western blot analysis. As shown in Figure $5 \mathrm{~A}$, we observed the upregulation of Fas, a death receptor, and Bax, a pro-apoptotic Bcl-2 family protein, in a dose-dependent manner. Activation of caspases, including caspase-3, -8 and -9 , and the cleavage of PARP occurred by EEOM treatment in a dose-dependent manner (Fig. 5B).

\section{DISCUSSION}

In the present study, the anti-cancer activity of $\mathrm{O}$. matsu- 
muranus extract and molecular mode of action were investigated. We firstly found that EEOM inhibits the proliferation of human hepatocellular carcinoma HepG2 cells by inducing G2/M cell cycle arrest and apoptosis.

Cell cycle dysregulation is a critical characteristic of tumor cells and regulation of proteins mediated cell cycle processes is an important strategy for the chemoprevention and chemotherapy of cancer. ${ }^{21,22}$ DNA damage or incomplete DNA replication brings about the inactivation of cell cycle checkpoint proteins, resulting in the inhibition of cell cycle progression to get the time required for DNA repair. ${ }^{23}$ Cell cycle progression is highly regulated by a series of cell cycle checkpoint proteins, the cyclins and CDKs. ${ }^{24,25}$ Among various cell cycle checkpoint proteins, a complex between CDK1 and cyclin A or CDK1 and cyclin B is involved in the process of G2/M transition. ${ }^{26,27}$ The activity of $\mathrm{CDK} /$ cyclin complex is negatively regulated to induce cell cycle arrest by $\mathrm{p} 53$-dependent or p53-independent pathway. In the case of p53-dependent pathway, a CDK inhibitor, p21, was induced by p53 increased in DNA damaged cells for cell cycle arrest and then non-repaired cells may be eliminated by apoptosis via inducing Bax and repressing Bcl-2 activity. ${ }^{28}$ On the other hand, in p53-independent pathway, damage signals of cells inactivate Cdc25C, an activator of CDK1/ cyclin B complex. . $^{2930}$

Our data revealed that $50 \mu \mathrm{g} / \mathrm{mL}$ and $100 \mu \mathrm{g} / \mathrm{mL}$ of EEOM induced HepG2 cell accumulation in G2/M phase and subG1 phase, respectively. These results suggest that EEOM-mediated cell cycle arrest is followed by apoptosis. Western blot analysis showed that EEOM increased the expression of p53 and p21, a CDK inhibitor, leading to G2/M arrest. The phosphorylation of CHK2 and p53 was also increased by EEOM, indicating that activated CHK2 triggers p53 phosphorylation to increase the stability of $\mathrm{p}^{53}$. $^{31,32}$ However, EEOM did not show any big difference in the protein levels of $\mathrm{Cdc} 25 \mathrm{C}$. These results suggest that EEOM-mediated G2/M arrest occurs by inhibition of CDK/ cyclin complex via p53-dependent p21 induction. In addition, immunofluorescence staining using antibody against actin and DAPI identified that EEOM-treated HepG2 cells have double nuclei and condensed actin, showing cell rounding. Based on the reports that the actin cytoskeleton of eukaryotic cells undergoes dynamic changes and remodeling during cell division cycle and apoptosis, ${ }^{33.34}$ our data suggest that EEOM may suppress the cytokinesis during the mitosis and cause the cytoskeletal changes to finally induce cell rounding, one of the characteristics of apoptosis.

Furthermore, EEOM-mediated apoptosis was also confirmed by Annexin V/7-AAD double staining, nuclear condensation and
DNA fragmentation. Caspases, a family of cysteine proteases, are involved in apoptosis and activated by cleavage at a posttranslational level. ${ }^{35}$ It has been well defined that apoptosis is induced by extrinsic and intrinsic pathways and increased Fas can activate caspase- 8 and caspase- 3 cascade via extrinsic pathway. ${ }^{36}$ By intrinsic pathway, released cytochrome $\mathrm{c}$ forms apoptosome with apoptotic protease activating factor-1, leading to cleavage of caspase- 9 and activation of caspase- $3 .{ }^{37}$ In this study, EEOM increased the expression of Fas and Bax, a pro-apoptotic member of Bcl-2 family. The caspase cascade, such as caspase-8, caspase-9, and caspase-3, was also activated by EEOM. These results strongly demonstrated that EEOM can induce apoptosis via both extrinsic and intrinsic pathways in HepG2 cells.

In conclusion, we found that EEOM efficiently induces cell cycle arrest at G2/M phase and apoptosis via both extrinsic and intrinsic pathways in HepG2 cells, followed by the suppression of cell proliferation. Our results show the anti-cancer activity of EEOM and its mode of action, which suggests that EEOM may be a possible nutraceutical candidate for chemoprevention and chemotherapy of cancer. Further studies will be required to identify the bioactive compound(s) of EEOM for its anti-cancer effect.

\section{ACKNOWLEDGMENTS}

This work was supported by the Dong-Eui University Grant (2015AA102) and Blue-Bio Industry Regional Innovation Center (RIC08-06-07) at Dong-Eui University as a RIC program under Ministry of Trade, Industry and Energy (MOTIE) and Busan city.

\section{CONFLICTS OF INTEREST}

No potential conflicts of interest were disclosed.

\section{REFERENCES}

1. Jemal A, Bray F, Center MM, Ferlay J, Ward E, Forman D. Global cancer statistics. CA Cancer J Clin 2011;61:69-90.

2. Stewart BW, Wild CP. World cancer report 2014. International Agency for Research on Cancer (IARC). Geneva, World Health Organization, 2014.

3. Neergheen VS, Bahorun T, Taylor EW, Jen LS, Aruoma OI. Targeting specific cell signaling transduction pathways by dietary and medicinal phytochemicals in cancer chemoprevention. Toxicology 2010;278:229-41.

4. Bishayee A, Thoppil RJ, Waghray A, Kruse JA, Novotny NA, Darvesh AS. Dietary phytochemicals in the chemoprevention and treatment of hepatocellular carcinoma: in vivo evidence, mo- 
lecular targets, and clinical relevance. Curr Cancer Drug Targets 2012;12:1191-232.

5. Landis-Piwowar KR, Iyer NR. Cancer chemoprevention: current state of the art. Cancer Growth Metastasis 2014;7:19-25.

6. Singh S, Singh PP, Roberts LR, Sanchez W. Chemopreventive strategies in hepatocellular carcinoma. Nat Rev Gastroenterol Hepatol 2014;11:45-54.

7. Hanahan D, Weinberg RA. The hallmarks of cancer. Cell 2000; 100:57-70.

8. Stewart ZA, Westfall MD, Pietenpol JA. Cell-cycle dysregulation and anticancer therapy. Trends Pharmacol Sci 2003:24:139-45.

9. Sun H, Hou H, Lu P, Zhang L, Ge C, Wang T, et al. Isocorydine inhibits cell proliferation in hepatocellular carcinoma cell lines by inducing $\mathrm{G} 2 / \mathrm{m}$ cell cycle arrest and apoptosis. PLoS One 2012;7:e36808.

10. Yoon JS, Woo HC, Kim HR, Kim GD. The extracts of Sargassum fulvellum induce pro-apoptosis and cell cycle arrest on MDA-MB231 human breast carcinoma cells. Cancer Prev Res 2010;15:52-9.

11. Hong JY, Chung HJ, Bae SY, Trung TN, Bae K, Lee SK. Induction of Cell Cycle Arrest and Apoptosis by Physcion, an Anthraquinone Isolated From Rhubarb (Rhizomes of Rheum tanguticum), in MDA-MB-231 Human Breast Cancer Cells. J Cancer Prev 2014;19: 273-8.

12. Visanji JM, Thompson DG, Padfield PJ. Induction of G2/M phase cell cycle arrest by carnosol and carnosic acid is associated with alteration of cyclin A and cyclin B1 levels. Cancer Lett 2006;237: 130-6.

13. Abraham RT. Cell cycle checkpoint signaling through the ATM and ATR kinases. Genes Dev 2001;15:2177-96.

14. Taylor WR, Stark GR. Regulation of the G2/M transition by $\mathrm{p} 53$. Oncogene 2001;20:1803-15.

15. Taylor RC, Cullen SP, Martin SJ. Apoptosis: controlled demolition at the cellular level. Nat Rev Mol Cell Biol 2008:9:231-41.

16. Fulda S, Debatin KM. Extrinsic versus intrinsic apoptosis pathways in anticancer chemotherapy. Oncogene 2006;25:4798-811.

17. Adams JM, Cory S. The Bcl-2 apoptotic switch in cancer development and therapy. Oncogene 2007;26:1324-37.

18. Fulda S. Targeting apoptosis for anticancer therapy. Semin Cancer Biol 2015;31:84-8.

19. Hung CY, Tsai YC, Li KY. Phenolic antioxidants isolated from the flowers of Osmanthus fragrans. Molecules 2012;17:10724-37.

20. Kwon HJ, Lee EW, Hong YK, Yun HJ, Kim BW. Widdrol from Juniperus chinensis induces apoptosis in human colon adenocarcinoma HT29 cells. Biotechnol Bioprocess Eng 2010;15: 167-72.

21. Cordon-Cardo C. Mutations of cell cycle regulators. Biological and clinical implications for human neoplasia. Am J Pathol 1995;147:
$545-60$.

22. Hall M, Peters G. Genetic alterations of cyclins, cyclin-dependent kinases, and Cdk inhibitors in human cancer. Adv Cancer Res 1996;68:67-108.

23. Zhou BB, Elledge SJ. The DNA damage response: putting checkpoints in perspective. Nature 2000;408:433-9.

24. Arellano M, Moreno S. Regulation of CDK/cyclin complexes during the cell cycle. Int J Biochem Cell Biol 1997;29:559-73.

25. Vermeulen K, Berneman ZN, Van Bockstaele DR. Cell cycle and apoptosis. Cell Prolif 2003;36:165-75.

26. Nurse P. Universal control mechanism regulating onset of M-phase. Nature 1990;344:503-8.

27. Wolgemuth DJ, Lele KM, Jobanputra V, Salazar G. The A-type cyclins and the meiotic cell cycle in mammalian male germ cells. Int J Androl 2004;27:192-9.

28. Miyashita T, Krajewski S, Krajewska M, Wang HG, Lin HK, Liebermann DA, et al. Tumor suppressor $\mathrm{p} 53$ is a regulator of bcl-2 and bax gene expression in vitro and in vivo. Oncogene 1994:9:1799-805.

29. Su CC, Lin JG, Chen GW, Lin WC, Chung JG. Down-regulation of Cdc25c, CDK1 and Cyclin B1 and up-regulation of Wee1 by curcumin promotes human colon cancer colo 205 cell entry into G2/M-phase of cell cycle. Cancer Genom Proteom 2006;3:55-62.

30. Boutros R, Lobjois V, Ducommun B. CDC25 phosphatases in cancer cells: key players? Good targets? Nat Rev Cancer 2007;7:495507.

31. Shieh SY, Ikeda M, Taya Y, Prives C. DNA damage-induced phosphorylation of p53 alleviates inhibition by MDM2. Cell 1997;91: 325-34.

32. Ashcroft M, Kubbutat MH, Vousden KH. Regulation of p53 function and stability by phosphorylation. Mol Cell Biol 1999;19: 1751-8.

33. Heng YW, Koh CG. Actin cytoskeleton dynamics and the cell division cycle. Int J Biochem Cell Biol 2010;42:1622-33.

34. Desouza M, Gunning PW, Stehn JR. The actin cytoskeleton as a sensor and mediator of apoptosis. Bioarchitecture 2012;2:75-87.

35. Stennicke HR, Salvesen GS. Caspases: controlling intracellular signals by protease zymogen activation. Biochim Biophys Acta 2000;1477:299-306.

36. Kim KH, Seo HS, Choi HS, Choi I, Shin YC, Ko SG. Induction of apoptotic cell death by ursolic acid through mitochondrial death pathway and extrinsic death receptor pathway in MDA-MB-231 cells. Arch Pharm Res 2011;34:1363-72.

37. Shangguan WJ, Li H, Zhang YH. Induction of G2/M phase cell cycle arrest and apoptosis by ginsenoside Rf in human osteosarcoma MG-63 cells through the mitochondrial pathway. Oncol Rep 2014:31:305-13. 